\title{
Simplified cascade multiphase DC-DC boost power converters for high voltage-gain and low-ripple applications
}

\author{
Pekik Argo Dahono \\ School of Electrical Engineering and Informatics, Institute of Technology Bandung, Indonesia
}

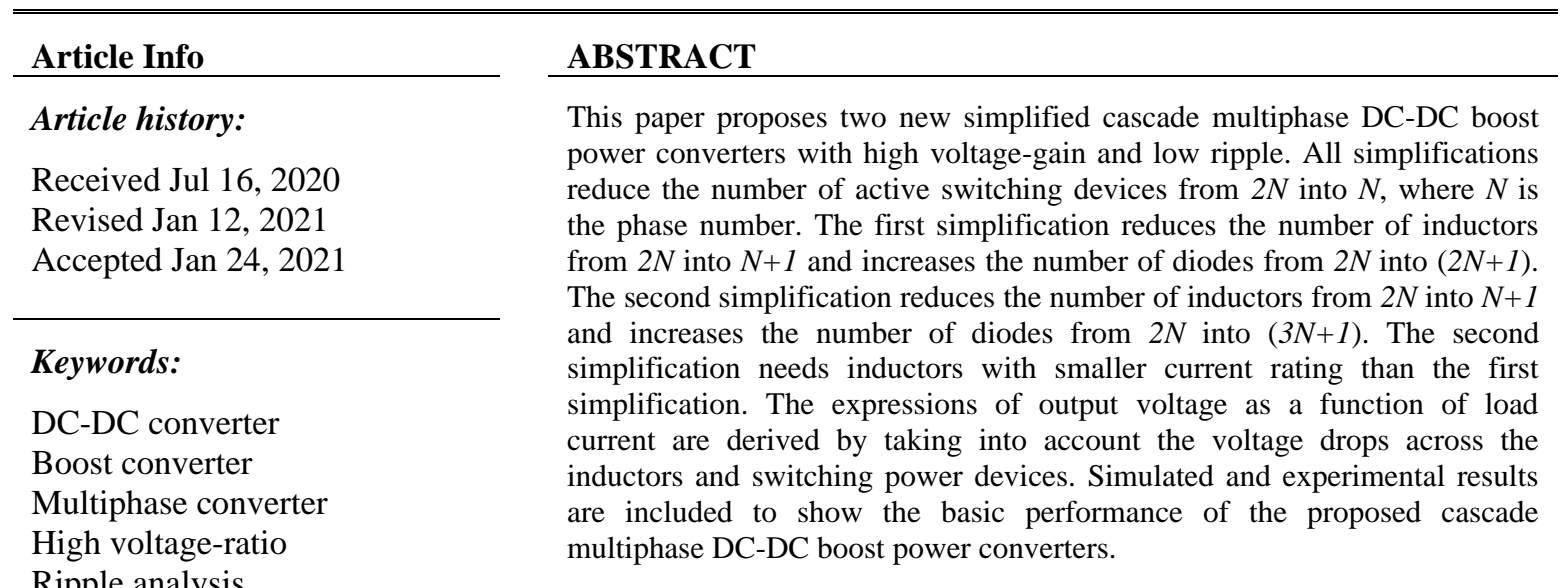

This is an open access article under the CC BY-SA license.

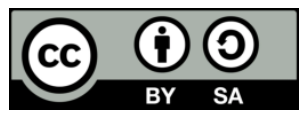

\section{Corresponding Author:}

Pekik Argo Dahono

School of Electrical Engineering and Informatics

Institute of Technology Bandung

Jl. Ganesa No. 10, Bandung 40132, Indonesia

Email: padahono@ieee.org

\section{INTRODUCTION}

A very high-gain step-up DC-DC power converter is commonly used in photovoltaic (PV) and fuelcell power generation systems. In a microconverter, for example, the output voltage of each PV module (about 36-42 Vdc) has to be increased directly into $400 \mathrm{Vdc}$. By using a microconverter, each module has own MPPT (maximum power point tracking) controller to minimize the effects of shading. Depending on the number of stacks, the dc output voltage of fuel cells is also very low between 12 and $60 \mathrm{Vdc}$ [1]. In addition to high voltage-gain, high efficiency and minimum input and output ripples are desirable. High voltage-gain capabilities are usually obtained by cascading several two or more DC-DC boost power converters. Minimum input and output ripples can be obtained by using multiphasing or interleaving technique. A very low input current ripple is necessary to ensure the long life of PV modules and fuel cells. High efficiency can be obtained by using soft switching techniques and eliminating the isolation transformer.

Cascade connection of several DC-DC boost power converters to increase the reachable voltagegain were discussed in [2]-[4]. These works have shown that different power converters can be cascaded to achieve certain properties. Simplification to reduce the number of active switching devices was proposed in [5]-[10]. These works are limited to single-phase DC-DC power converters. Cascade connection of several multiphase DC-DC boost power converters to reduce the input current ripple were also presented in [11][12]. By cascading several multiphase DC-DC boost power converters, a zero input current ripple can also be achieved as well as very high voltage-gain. Cascading several multiphase DC-DC boost power converters, however, needs a large number of inductors and active switching devices. As far as the author is aware, how 
to reduce the component count of cascade multiphase DC-DC boost power converters has not been proposed. Another method to increase the voltage gain is by using a dual boost topology [13]-[15]. In this case, the inputs of two boost converters are connected in parallel and the outputs are in series. The main disadvantage of this approach is that there is no common point between the input and output terminals.

This paper proposes two new simplified cascade multiphase DC-DC boost power converters with very high voltage-gain and low input current ripple. All simplifications reduce the number of active switching power devices from $2 N$ into $N$, where $N$ is the phase number. The first simplification reduces the number of inductors from $2 N$ into $(N+1)$ and increases the number of diodes from $2 N$ into $(2 N+1)$. The second simplification reduces the number of inductors from $2 N$ into $N+1$ and increases the number of diodes from $2 N$ into $(3 N+1)$. The expressions of output voltage as a function of load current are derived by taking into account the voltage drops across the inductors and switching power devices. A comparative evaluation among cascade multiphase DC-DC boost power converters is provided. Simulated and experimental results are included to show the basic performance of the proposed cascade multiphase DC-DC boost power converters.

The rest of the paper is organized as follows. Section two discuss the conventional cascade singlephase and multiphase DC-DC boost converters. Section three discuss the derivation of two new simplified cascade multiphase DC-DC boost converters. Section four discuss the performance comparison among the cascade multiphase DC-DC boost power converters. Section five discuss the experimental results and Section six is the conclusion.

\section{CONVENTIONAL CASCADE MULTIPHASE DC-DC POWER CONVERTERS}

Conventional cascade multiphase DC-DC boost power converters are first discussed here. Simplification of these converters are discussed in the next section. Figure 1 shows the cascade connection of single-phase DC-DC boost power converters and the simplified version. By using the cascade connection as shown in Figure 1(a), the voltage-gain under continuous inductor current mode is (1)

$$
\frac{V_{o}}{E_{d}}=\frac{1}{\left(1-\alpha_{1}\right)\left(1-\alpha_{2}\right)}
$$

where $\alpha_{1}$ and $\alpha_{2}$ are the duty cycles of the front and rear converter switching power devices, respectively. The maximum value of duty cycle is unity.

Simplification method of cascaded connection of two DC-DC boost converter in Figure 1(a) into the one as shown in Figure 1(b) was discussed in [5]-[10]. As it is shown in Figure 1(b), the simplified cascade single-phase DC-DC boost power converter needs just one active switching power devices but the number of diodes is increased into three. Under continuous inductor current mode, the voltage gain is (2)

$$
\frac{V_{o}}{E_{d}}=\frac{1}{(1-\alpha)^{2}}
$$

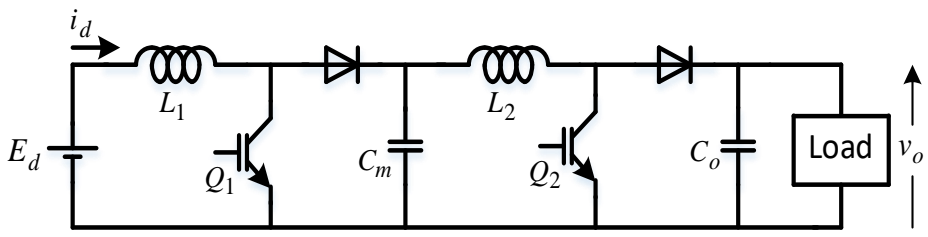

(a)

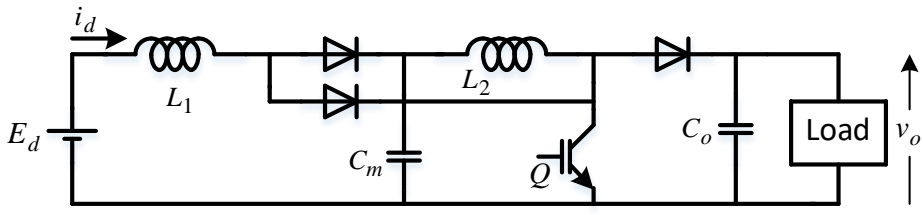

(b)

Figure 1. Cascade connection of single-phase DC-DC boost converters, (a) cascade connection of singlephase DC-DC boost converters, (b) simplified cascade single-phase DC-DC boost converters 
Thus, the voltage-gain of simplified cascade single-phase DC-DC boost converter has a quadratic characteristic. Analysis and control this quadratic converter have been proposed in [16]-[18]. For the same duty cycle, the original and simplified cascade single-phase DC-DC boost power converters have a voltagegain that is higher than just a single-phase DC-DC boost power converter. This cascade connection can be extended to more than two DC-DC boost power converters. Though cascading several DC-DC boost converters can solve the voltage-gain problem, the input and output ripples are still high. In single-phase DCDC boost converter, the ripples are usually reduced by increasing the switching frequency and/or the filter size.

It has been shown in the literature that multiphasing or interleaving is an effective way to reduce the input and output current ripples without using a high switching frequency nor a large filter [19]-[21]. Similarly, in order to reduce the input and output ripples and to obtain a high voltage-gain, two or more multiphase DC-DC boost power converters can be cascaded as shown in Figure 2. By using this cascade connection, the voltage-gain is the same as given by (1). The phase numbers of front and rear multiphase DCDC boost power converters in Figure 2 do not have to be the same. If the duty cycle of the first stage converter is selected constant at certain values, the input current ripple can be almost equal to zero [20]. In this case, the output voltage control is delegated into the rear stage DC-DC boost power converter. The switching frequencies of the front and rear stages of DC-DC boost power converters do not have to be the same and can be optimized to maximize the efficiency. Though the input output ripples are reduced significantly by cascading several multiphase DC-DC boost power converters, the numbers of inductors and switching devices are significantly increased.

The simplified single-phase cascade DC-DC power converter in Figure 1(b) can also be extended into the multiphase one as shown in Figure 3. Similar to conventional multiphase DC-DC boost converters, the active switching devices are gated by identical carrier signals with phase difference of $2 \pi / N$. The voltagegain of this converter is the same as given by (2). Though the number of active switching power devices is reduced from $2 N$ into $N$, the number of diodes is increased from $2 N$ into $3 N$ and the number of electrolytic capacitors is increased from two into $N+1$.

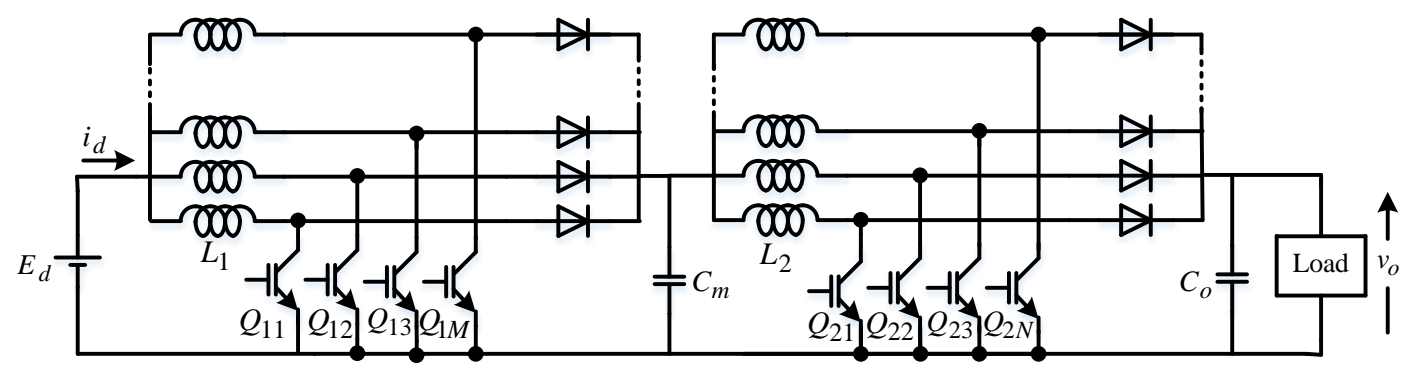

Figure 2. Cascade connection of multiphase DC-DC boost converters

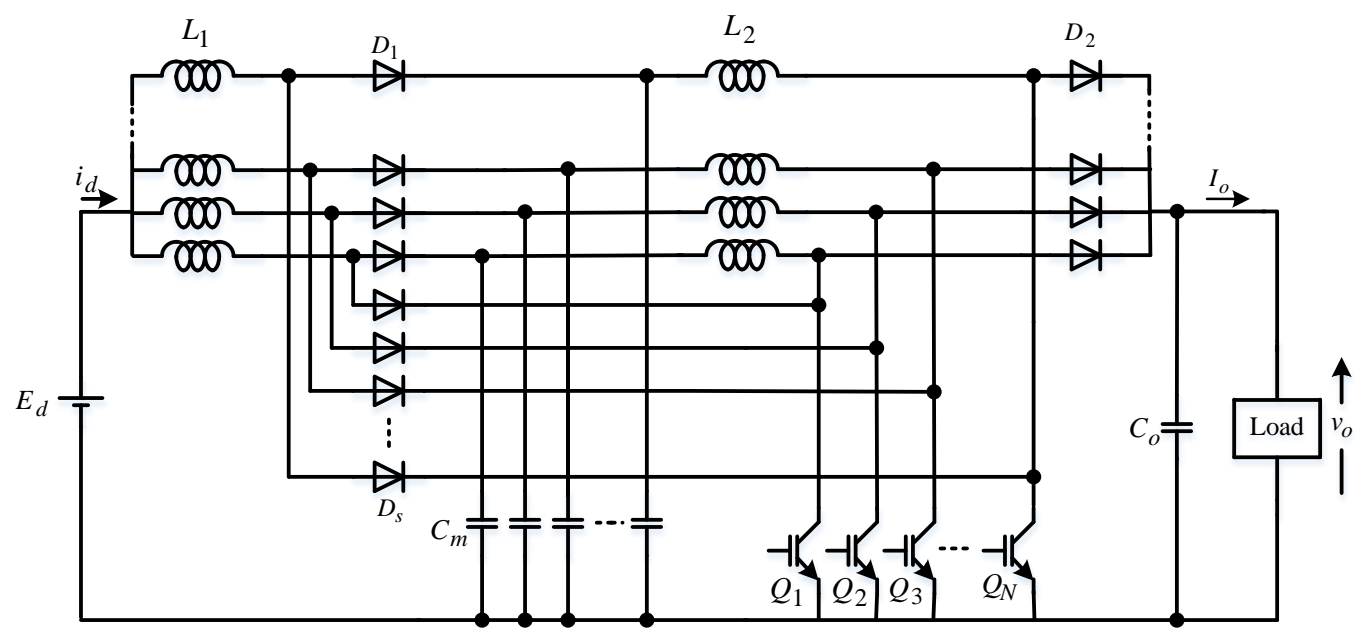

Figure 3. Simplified cascade multiphase DC-DC boost converters 


\section{SIMPLIFIED CASCADE MULTIPHASE DC-DC POWER CONVERTERS}

\subsection{First simplification}

As the duty cycles of transistors in Figure 3 are equals, the average voltages across capacitors $\mathrm{Cm}$ are equal. As the voltages are equal, the capacitors $C_{m}$ can be connected directly in parallel. If these capacitors $C_{m}$ are connected in parallel, the inductors $L_{l}$ and diodes $D_{l}$ will also be in parallel. Thus, the converter can be simplified into the first simplified cascade multiphase DC-DC boost converter as shown in Figure 4.

In the new converter of Figure 4, the number of inductors is reduced from $2 N$ into $(N+1)$. The active switching power devices are reduced from $2 N$ into $N$. The number of diodes, however, is increased from $2 N$ into $(2 N+1)$ compared to the one in Figure 2. Similar to conventional multiphase DC-DC boost converter, the same gating strategy as conventional multiphase dc- dc boost converter is used here. Under continuous inductor current mode, the voltage-gain is (3)

$$
\frac{V_{o}}{E_{d}}=\frac{1}{(1-N \alpha)(1-\alpha)}
$$

where the maximum value of duty cycle is $1 / N$. If the duty cycle is more than $1 / N$, the input voltage will be short-circuited through the active switching devices.

As the maximum duty cycle is reduced, the phase number can't be increased too high. In the DC-DC power converter of Figure 4, the number of inductors of the front stage DC-DC boost power converter has been reduced from $N$ into one. Moreover, the required inductance to ensure continuous conduction mode is also $1 / N$ smaller compared to the original one. In this case, however, the required current rating of the inductor will be large as the front DC-DC boost converter works at the low voltage side.

Figure 5 shows simulated result for the converter in Figure 4 with phase number of two. The converter was simulated by using PSIM. In the simulation, it is assumed that dc voltage source is $12 \mathrm{~V}$. The inductors $L_{1}$ and $L_{2}$ are equal with the inductance of one $\mathrm{mH}$. The capacitors $C_{m}$ and $C_{o}$ are equal with the capacitance of $200 \mathrm{uF}$. The switching frequency is $5 \mathrm{kHz}$. In the simulation, it is also assumed that all components are ideal components. The load is assumed as a constant resistance of $100 \mathrm{Ohm}$. Figure 5 shows that the ripple frequency of the input current is two times of the switching device frequency. The duty cycle of 0.41 is used to obtain an output voltage of $120 \mathrm{Vdc}$. As the input side inductor current ripple is $N$ times of the switching device frequency, the size of the inductor can be reduced significantly.

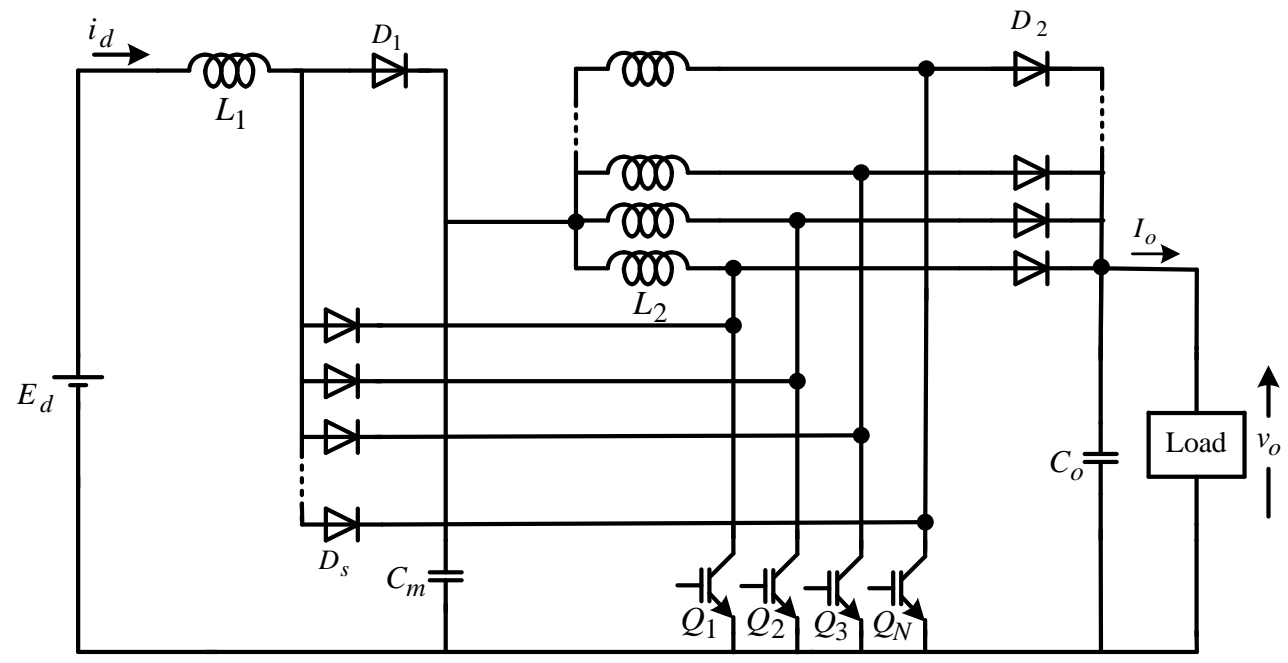

Figure 4. First simplified cascade multiphase DC-DC boost converter 


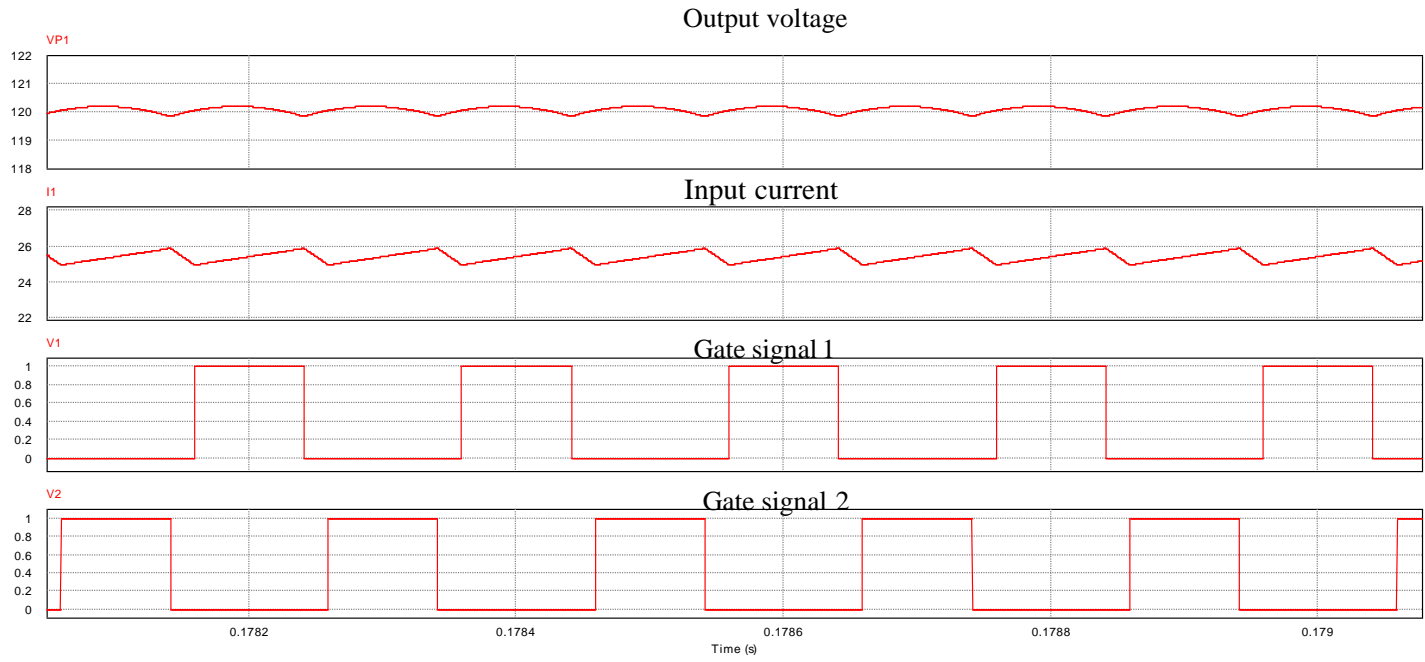

Figure 5. Simulated result of first simplified cascade two-phase DC-DC boost converter

\subsection{Second simplification}

As it was previously mentioned, the average voltages across capacitors $C_{m}$ are equal when the duty cycles of switching devices are equal. Thus, the inductors $L_{2}$ and $D_{2}$ will be connected in parallel. As connected in parallel, $N$ inductors $L_{2}$ and diodes $D_{2}$ can be replaced into just single inductor $L_{2}$ and single diode $D_{2}$ as shown in Figure 6. In this case, however, additional series diodes are required to prevent currents from inductors $L_{1}$ are flowing through the undesired transistors. The numbers of inductors and active switching power devices are also reduced as in the case of Figure 4. The number of diodes, however, is increased from $2 N$ into $(3 N+1)$. In this case, however, the single inductor is working on the high voltage side and, therefore, the required current rating is small. Moreover, the ripple frequency of the current through the second stage inductor is $N$ times of the switching frequency and, therefore, the required inductance is small. The voltage-gain is still the same as given by (3).

Figure 7 shows simulated result for the converter in Figure 6 with phase number of two. In the simulation, the system data is the same as the used in Figure 5. Figure 7 shows that the ripple frequency of the input current is two times of the switching device frequency and also two times of the input side inductor current ripple. The duty cycle of 0.41 is used to obtain an output voltage of $120 \mathrm{Vdc}$.

It has been mentioned that the maximum duty cycle will be significantly reduced when the phase number is high. In order to solve this problem, an even phase number can be obtained by paralleling several simplified cascade two-phase DC-DC boost converters. Figure 8 shows simplified cascade four-phase DCDC boost converter that is obtained by paralleling two simplified cascade two-phase DC-DC boost converters. The carrier signals for the first and second simplified cascade two-phase DC-DC boost converters are shifted by $90 \mathrm{o}$ in order to obtain four phase DC-DC boost converter characteristic. The voltage gain of this converter is (4)

$$
\frac{V_{o}}{E_{d}}=\frac{1}{(1-2 \alpha)(1-\alpha)}
$$

By using this method, the maximum duty cycle is half instead of one fourth.

The proposed simplification approach can also be applied to cascade connection of more than two multiphase DC-DC boost power converters. Figure 9 shows the extension of Figure 4 when the number of stages is three. In this case, the voltage gain under continuous inductor current mode is (5)

$$
\frac{V_{o}}{E_{d}}=\frac{1}{(1-N \alpha)^{2}(1-\alpha)}
$$

Extension of the scheme in Figure 6 into more than two stages will need more inductors than the extension of Figure 4. Thus, extension of Figure 4 is preferred when the number of stages is more than two. 


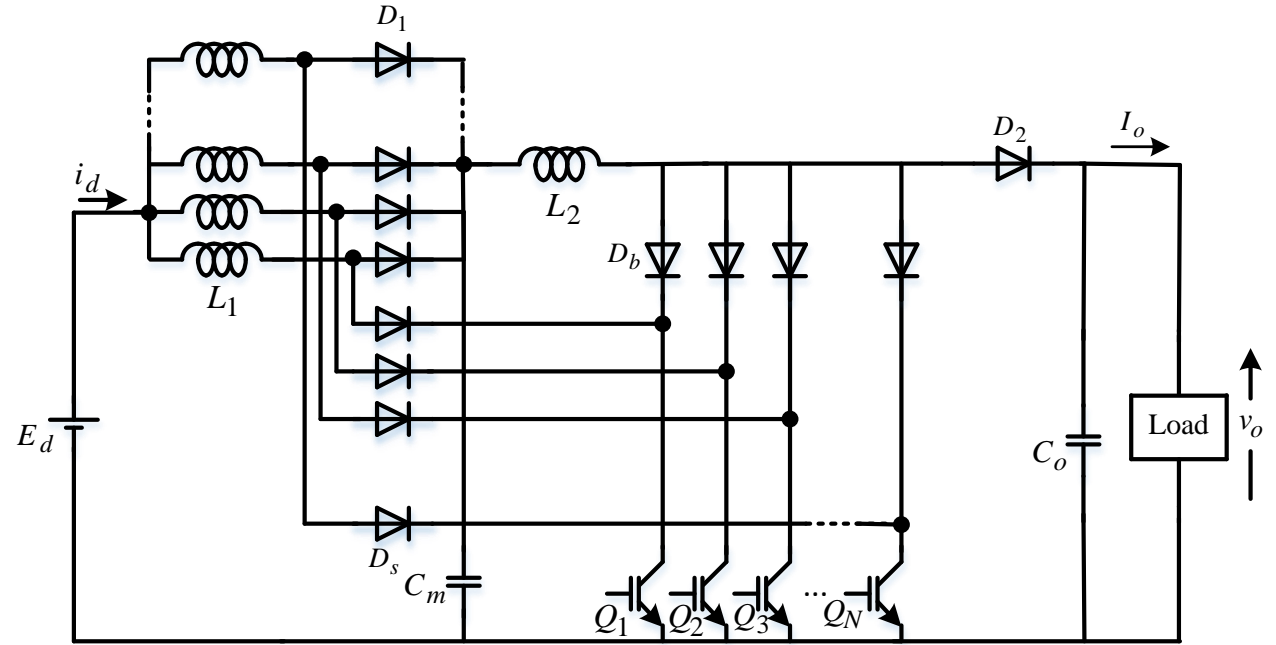

Figure 6. Second simplified cascade multiphase DC-DC boost converter

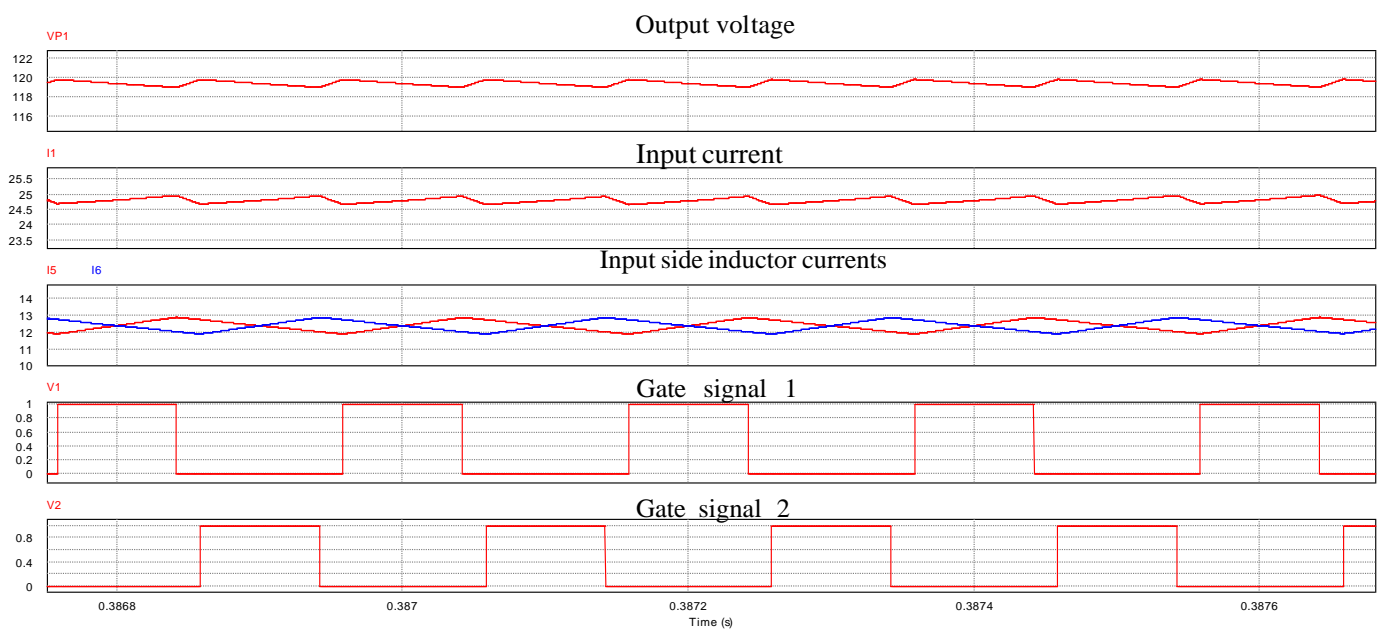

Figure 7. Simulated result of second simplified cascade two-phase DC-DC boost converter

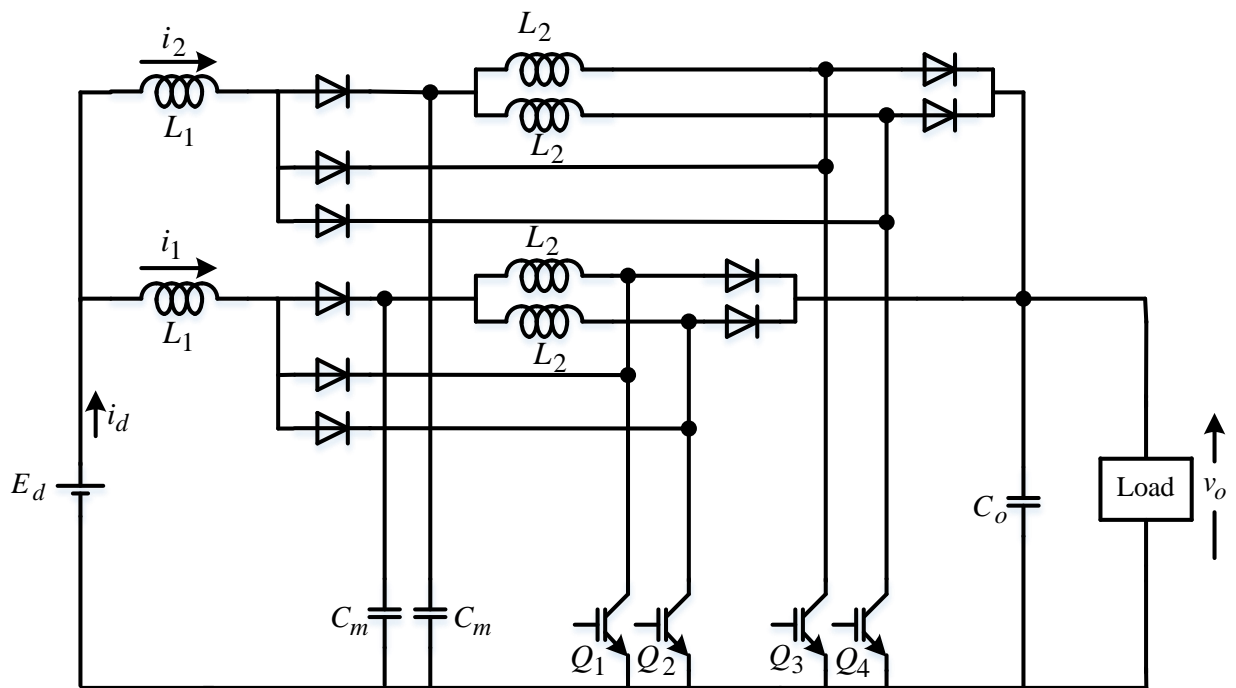

Figure 8. Simplified cascade four-phase DC-DC boost converter 


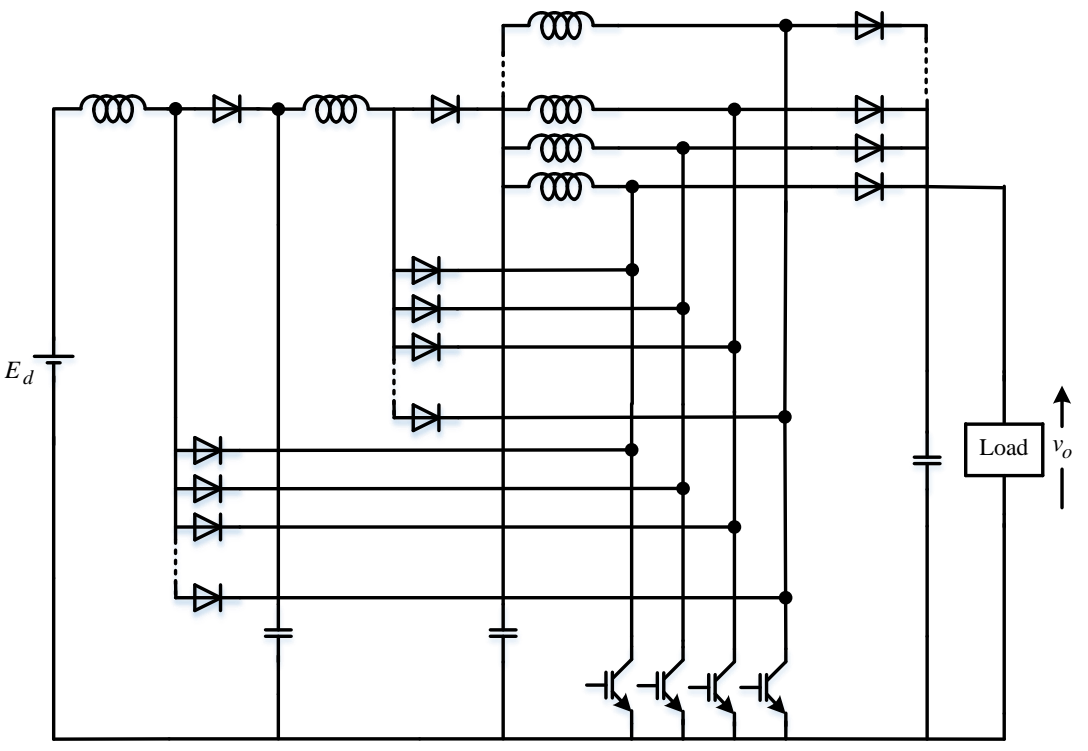

Figure 9. Simplified three-stages cascade multiphase DC-DC boost converter

\section{COMPARATIVE EVALUATION}

\subsection{Output voltage analysis}

The output voltage expressions (1)-(3) have been derived by assuming that the voltage drops across the inductors and switching power devices are negligible. If these voltage drops are neglected, the output voltage can be increased up to infinitely. In practices, the voltage drops across the inductors and switching power devices will limit the maximum output voltage that can be achieved.

The expressions of output voltage by taking into account the voltage drops across the inductors and switching power devices can be obtained by using state-space averaging technique [22]. The obtained results are shown in Table 1. These expressions are valid under continuous inductor current mode. All capacitors were assumed as ideal capacitors with no parasitic components. All inductors have the same resistances of $R_{L}$. All active switching power devices and diodes are assumed as identical. The voltage drops across the switching devices during conduction mode are represented by a constant component plus a resistive component. $V_{Q}$ and $V_{D}$ are constant components and $R_{Q}$ and $R_{D}$ are resistive components of voltage drops across the transistors and diodes, respectively.

Table 1. Output voltage expressions

\begin{tabular}{|c|c|}
\hline Figure & Output voltage expression \\
\hline 2 & $\bar{v}_{o}=\frac{E_{d}}{(1-\alpha)^{2}}-\frac{\left[V_{Q} \alpha+V_{D}(1-\alpha)\right](2-\alpha)}{(1-\alpha)^{2}}-\frac{\left[R_{L}+R_{Q} \alpha+R_{D}(1-\alpha)\right]\left(2-2 \alpha+\alpha^{2}\right)}{N(1-\alpha)^{4}} I_{o}$ \\
\hline 3 & $\begin{aligned} \bar{v}_{o}= & \frac{E_{d}}{(1-\alpha)^{2}}-\frac{V_{Q} \alpha(2-\alpha)+V_{D}\left(2-2 \alpha+\alpha^{2}\right)}{(1-\alpha)^{2}}-\frac{R_{Q} \alpha(2-\alpha)^{2}}{N(1-\alpha)^{4}} I_{o} \\
& -\frac{R_{L}\left(2-2 \alpha+\alpha^{2}\right)}{N(1-\alpha)^{4}} I_{o}-\frac{R_{D}\left(2-3 \alpha+3 \alpha^{2}-\alpha^{3}\right)}{N(1-\alpha)^{4}} I_{o}\end{aligned}$ \\
\hline 4 & $\begin{array}{l}\bar{v}_{o}=\frac{E_{d}}{(1-N \alpha)(1-\alpha)}-\frac{V_{Q} \alpha[1+N-N \alpha]}{(1-N \alpha)(1-\alpha)}-\frac{V_{D}\left(2-\alpha-N \alpha+N \alpha^{2}\right)}{(1-N \alpha)(1-\alpha)}-\frac{\left.R_{L} \mid N+(1-N \alpha)^{2}\right\rfloor}{N(1-N \alpha)^{2}(1-\alpha)^{2}} I_{o} \\
-\frac{R_{D}\left[N+(1-\alpha)(1-N \alpha)^{2}\right]}{N(1-N \alpha)^{2}(1-\alpha)^{2}} I_{o}-\frac{R_{Q} \alpha\left(1+N+2 N^{2}-2 N \alpha-N^{2} \alpha-N^{3} \alpha+N^{2} \alpha^{2}\right)}{N(1-\alpha)^{2}(1-N \alpha)^{2}} I_{o}\end{array}$ \\
\hline 6 & $\begin{array}{l}\bar{v}_{o}=\frac{E_{d}}{(1-N \alpha)(1-\alpha)}-\frac{V_{Q} \alpha[1+N(1-\alpha)]+V_{D}(2-\alpha)}{(1-N \alpha)(1-\alpha)}-\frac{\left.R_{L} \mid 1+N(1-\alpha)^{2}\right]}{N(1-N \alpha)^{2}(1-\alpha)^{2}} I_{o} \\
-\frac{R_{D}\left[1+N(1-\alpha)^{2}\right]}{N(1-N \alpha)^{2}(1-\alpha)^{2}} I_{o}-\frac{R_{Q} \alpha\left[1+N+2 N^{2}-N \alpha-3 N^{2} \alpha+N^{2} \alpha^{2}\right]}{N(1-N \alpha)^{2}(1-\alpha)^{2}} I_{o}\end{array}$ \\
\hline
\end{tabular}


Output voltage expressions in Table 1 for the first and second simplified converters are plotted as shown in Figure 10. It is assumed that the active switching devices are MOSFETS (IRFP240). According to the data sheet, the resistance of IRFP240 is $18 \mathrm{~m} \Omega$. All diodes are RHRP3060 with a constant voltage drop of $0.9 \mathrm{~V}$ and a resistance of $16 \mathrm{~m} \Omega$. Inductor resistances are assumed equal to $50 \mathrm{~m} \Omega$. It is assumed that the dc input voltage is constant at $12 \mathrm{Vdc}$. The no load voltages are assumed the same at $120 \mathrm{Vdc}$. This figure shows that the output voltages of first and second simplified cascade multiphase DC-DC boost converters are higher than the ones in Figures 2 and 3. The voltage drops of first simplified converter are almost not changed when the phase number is increased. On the other hand, the voltage drops of the second simplified converter are increased when the phase number is increased. In practices, the inductors of the front and rear stages of the simplified converters will be different and can be optimized to reduce the voltage drops.

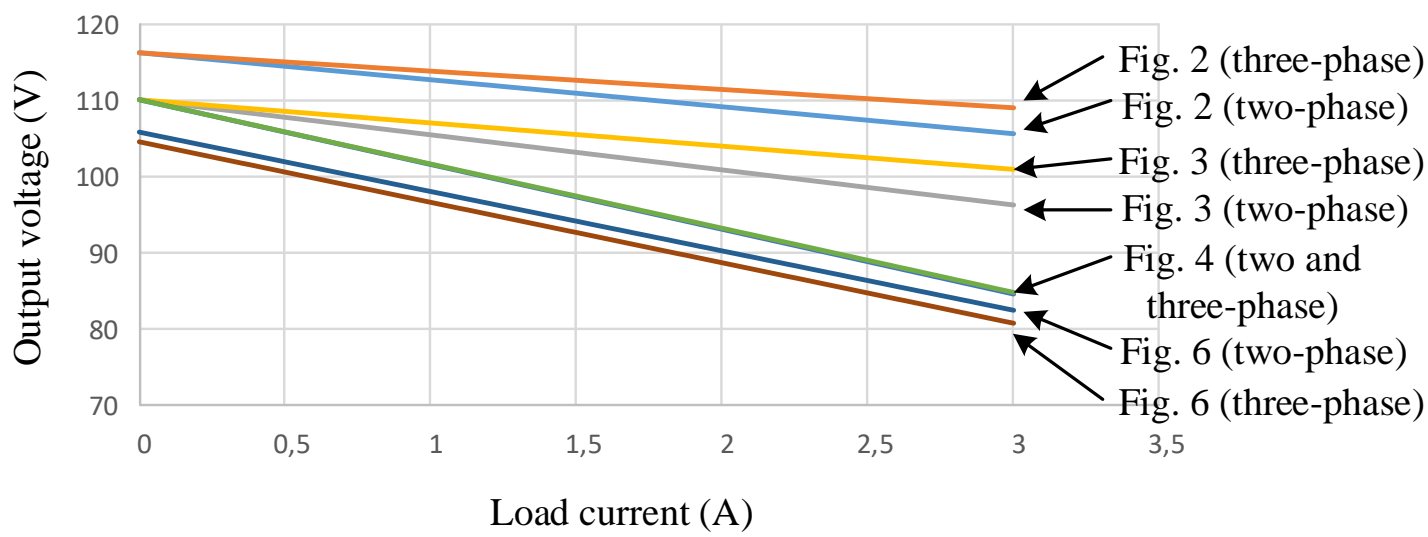

Figure 10. Output voltage as a function of load current

\subsection{Conduction losses}

The output power of the DC-DC power converter is (6)

$$
P_{o}=\bar{v}_{o} I_{O}
$$

By using the output voltage expression in Table 1 and (3), the output power of the simplified cascade multiphase DC-DC boost power converter, Figure 3 for example, is (7)

$$
\begin{aligned}
& P_{o}=\frac{E_{d}}{(1-\alpha)^{2}} I_{o}-\frac{V_{Q} \alpha(2-\alpha)+V_{D}\left(2-2 \alpha+\alpha^{2}\right)}{(1-\alpha)^{2}} I_{o} \\
& -\frac{R_{Q} \alpha(2-\alpha)^{2}+R_{D}\left(2-3 \alpha+3 \alpha^{2}-\alpha^{3}\right)+R_{L}\left(2-2 \alpha+\alpha^{2}\right)}{N(1-\alpha)^{4}} I_{o}^{2}
\end{aligned}
$$

The input current of the DC-DC power converter is (8)

$$
\bar{i}_{d}=\frac{I_{o}}{(1-\alpha)^{2}}
$$

Substituting (8) into (7), the (9) is obtained

$$
\begin{aligned}
& P_{o}=E_{d} \bar{i}_{d}-\frac{V_{Q} \alpha(2-\alpha)+V_{D}\left(2-2 \alpha+\alpha^{2}\right)}{(1-\alpha)^{2}} I_{o} \\
& -\frac{R_{Q} \alpha(2-\alpha)^{2}+R_{D}\left(2-3 \alpha+3 \alpha^{2}-\alpha^{3}\right)+R_{L}\left(2-2 \alpha+\alpha^{2}\right)}{N(1-\alpha)^{4}} I_{o}^{2}
\end{aligned}
$$


The power loss in the converter is (10)

$$
P_{\text {loss }}=P_{i}-P_{d}
$$

The converter input power is (11)

$$
P_{i}=E_{d} \bar{i}_{d}
$$

By using (8)-(11), the (12) is obtained:

$$
\begin{aligned}
& P_{\text {loss }}=\frac{V_{Q} \alpha(2-\alpha)+V_{D}\left(2-2 \alpha+\alpha^{2}\right)}{(1-\alpha)^{2}} I_{o} \\
& +\frac{R_{Q} \alpha(2-\alpha)^{2}+R_{D}\left(2-3 \alpha+3 \alpha^{2}-\alpha^{3}\right)+R_{L}\left(2-2 \alpha+\alpha^{2}\right)}{N(1-\alpha)^{4}} I_{o}^{2}
\end{aligned}
$$

Equation (12) shows that the voltage drops across the switching devices and inductors can be used to estimate the conduction losses. As the voltage drops in the simplified converters are bigger than the original ones, the conduction losses are also bigger. As it has been mentioned before, the inductor $L_{l}$ in Figure 4 or the inductor $L_{2}$ in Figure 6 can be made smaller and, therefore, the conduction losses can be smaller.

\subsection{Switching losses}

The switching losses are proportional to the operating voltage and current [23]-[27]. In general, the switching losses in a transistor can be written as (13)

$$
P_{S w}=K f_{s} V I
$$

where $K$ is a constant that depends on the device characteristics, $f_{s}$ is switching frequency, $V$ is the device operating voltage, and $I$ is the device current. By using a simple analysis, the expressions of switching losses of cascaded multiphase boost converters are given in Table 2. These expressions are plotted in Figure 11.

Figure 11 shows that the first simplified converter has higher switching losses than the others. Though the second simplified converter has higher conduction losses than the first one, the switching losses are smaller. In general, the proposed multiphase DC-DC boost converters have a smaller count number of components but at the expense of higher losses. The losses can be reduced if modern wide bandgap power devices are used [26], [27].

As the conduction and switching losses are high compared to conventional cascade multiphase DCDC boost power converters, the proposed simplified cascade multiphase DC-DC power converters are suitable only for low-power applications such as microconverters. Though the losses are high, the proposed converters need a smaller count of inductors and capacitors. In some cases, the inductors and capacitors take more volume than the semiconductors and the associated controllers.

Table 2. Switching losses

\begin{tabular}{cl}
\hline Figure & Output voltage expression \\
\hline 2 & $P_{s w}=2 K f_{s} E_{d} \frac{I_{L}}{(1-\alpha)^{3}}$ \\
3 & $P_{s w}=\frac{K f_{s} E_{d} I_{L}}{(1-\alpha)^{4}}(2-\alpha)$ \\
4 & $P_{s w}=\frac{K f_{s} E_{d} I_{L}}{(1-\alpha)^{2}(1-N \alpha)^{2}}[(1-N \alpha)+N]$ \\
6 & $P_{s w}=\frac{K f_{s} E_{d} I_{L}}{(1-\alpha)^{2}(1-N \alpha)^{2}}[N(1-N \alpha)+1]$ \\
\hline
\end{tabular}




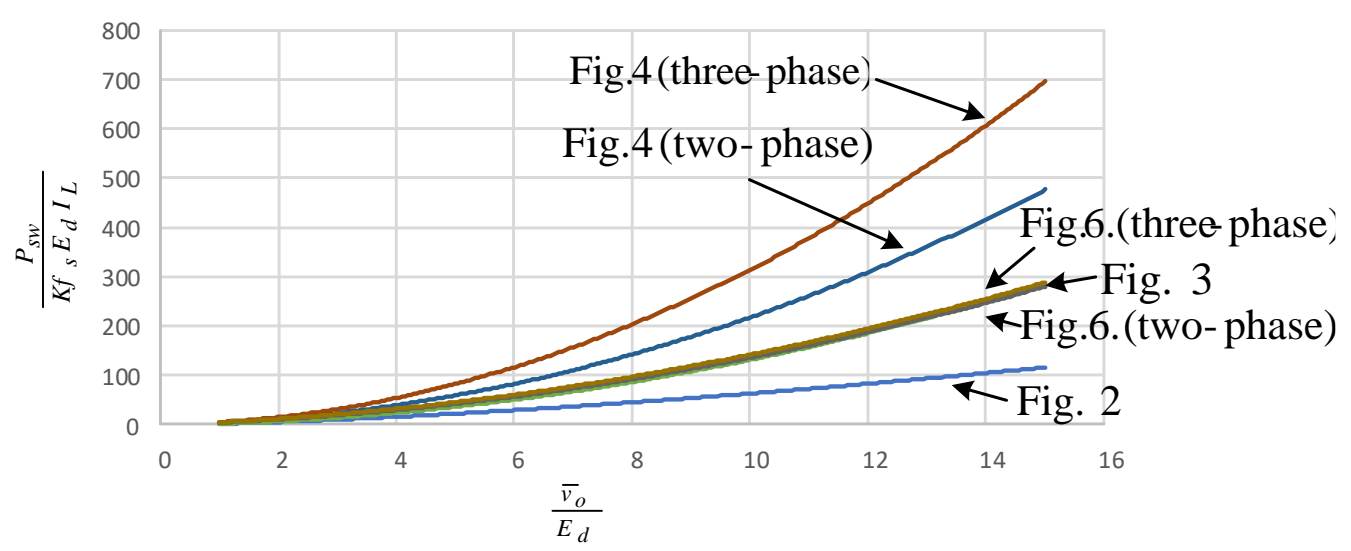

Figure 11. Switching losses

\section{EXPERIMENTAL RESULTS}

A small simplified cascade multiphase DC-DC boost converter system with the scheme as shown in Figure 4 was constructed. The phase number $N$ is two. All inductors have identical inductance of $5.1 \mathrm{mH}$ and resistance of $0.3 \mathrm{Ohm}$. The active switching devices were implemented by using power MOSFETs (IRFP240) with resistance of $18 \mathrm{~m} \Omega$. A TLP250 gate driver was used to drive the MOSFET. All diodes (RHRP3060) have constant voltage drop of $0.9 \mathrm{~V}$ and resistance of $16 \mathrm{~m} \Omega$. The switching frequency was maintained constant at $10 \mathrm{kHz}$ during the experiment. The dc input voltage is also maintained constant at 12 Vdc. The load is a variable resistance. No attempts have been done to optimize the converter performance by selecting better inductors and semiconductor devices.

Figure 12 shows the input current and gate signal waveforms of simplified cascade two-phase DCDC boost converter. It can be seen that the input current ripple frequency is twice the gate signal frequency. In this figure, $O$ is the zero point of current and $G$ is the zero point of gate signal.

Figure 13 shows the input current ripple as a function of voltage-gain when the load resistance is fixed at $100 \mathrm{Ohm}$. For comparison, the result of simplified cascade single-phase DC-DC boost converter is also shown. In this figure, the triangle and square marks are experimental results and lines are calculated results. The current ripples were calculated by a method as described in [20]. It can be seen that the input current ripple of simplified cascade two-phase DC-DC boost converter is much smaller than the single phase one. Discrepancies between calculated and measured results are possibly due to the nonlinearity of iron core inductors. The ripple can be reduced further by increasing the phase number.

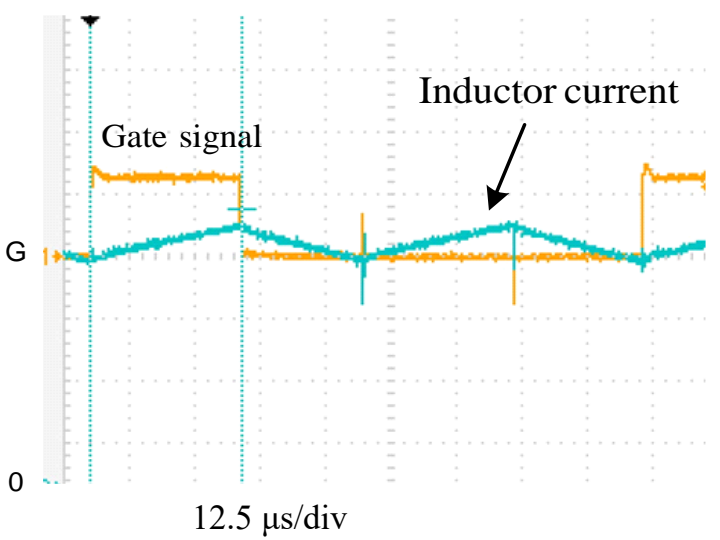

Figure 12. Input current (2 A/div) and gate signal (5 V/div) waveforms

Figure 14 shows the experimental and calculated results of voltage-gain as a function of duty cycle when the load resistance is fixed at $100 \mathrm{Ohm}$. Though the resistance of inductors is large, a voltage-gain 
more than eight can be reached easily by the proposed converter. Figure 14 also shows that the experimental results are close to the calculated ones. Higher voltage gain can be obtained by using number of stages more than two.

Figure 15 shows the output voltage as a function of the output current. The output current is changed by changing the load resistance while maintaining the duty cycle constant. In this figure, cross mark is experimental results and line is calculated results. Based on Figures 14 and 15, validity of the derived expression as shown in Table 1 can be appreciated. Discrepancies between calculated and measured results are possibly due to the inaccuracy of inductor resistances.

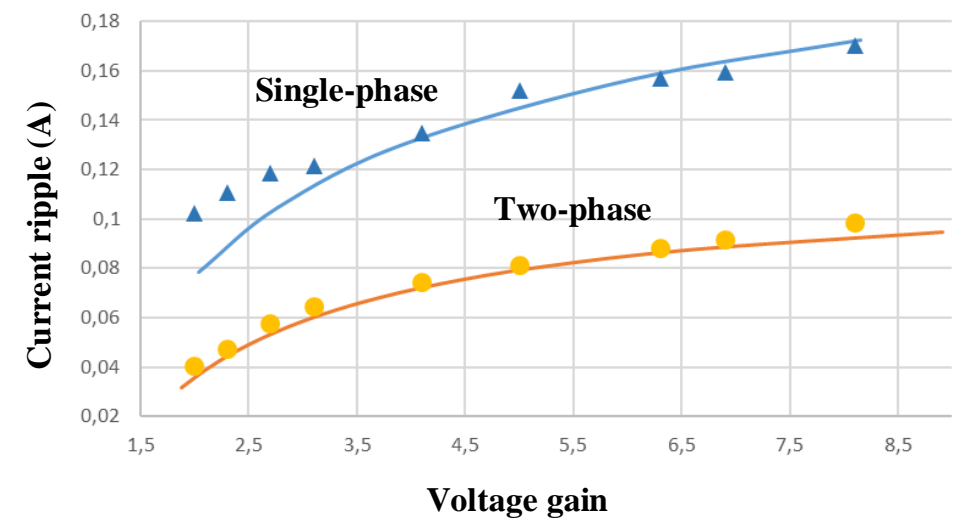

Figure 13. Input current ripple as a function of voltage-gain

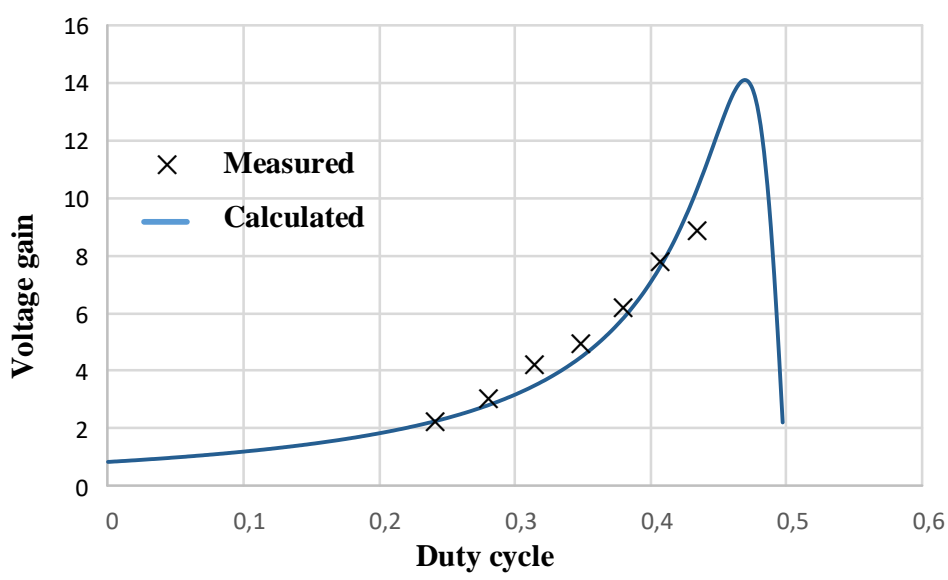

Figure 14. Voltage gain as a function of duty cycle

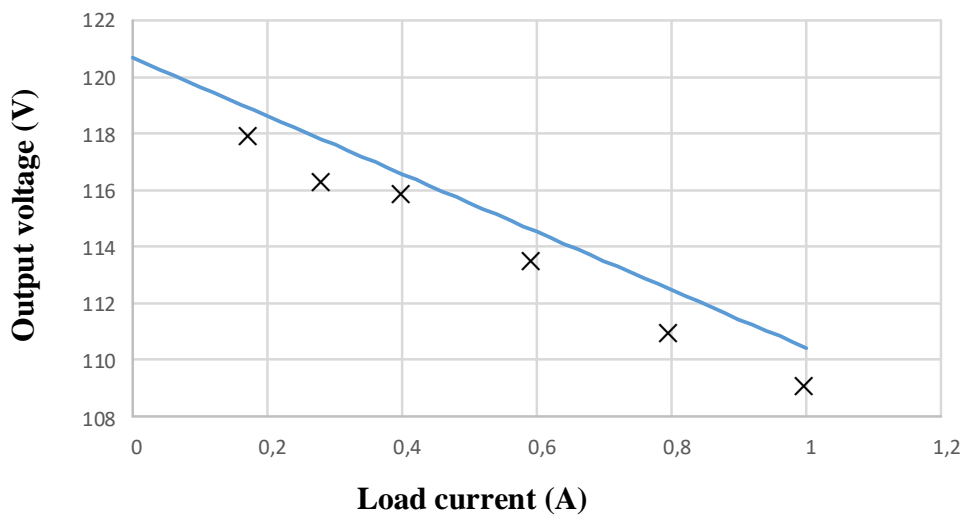

Figure 15. Output voltage as a function of load current 


\section{CONCLUSION}

Two simplified cascade multiphase DC-DC boost power converters for high voltage-gain and lowripple applications have been proposed in this paper. By using the proposed converters, high voltage-gain and small input and output ripples, can be obtained with a smaller number of active switching power devices. Voltage-gain comparison among the proposed converters is shown in this paper. A method is presented to solve the problem of limited duty cycle range when the phase number is high. The proposed method can also be extended to cascade connection more than two multiphase DC-DC boost converters. Output voltage analysis that is useful to estimate the conduction losses is also presented. As the power losses are higher than the conventional cascade multiphase DC-DC boost power converters, the proposed converters are suitable for low-power applications such as microconverters. Experimental results that showing the basic performance have been included. Selection of the optimal components for the proposed converters is under investigation.

\section{ACKNOWLEDGMENTS}

The author wishes to thank his students at the Institute of Technology Bandung, Indonesia, for their experimental results. A financial support from the LPDP is greatly appreciated.

\section{REFERENCES}

[1] H. Liu et al., "Short-term prognostics of PEM fuel cells: A comparative and improvement study," IEEE Trans. Ind. Electron, vol. 66, no. 8, pp. 6077-6086, Aug. 2019

[2] H. Matsuo and K. Harada, "The cascade connection of switching regulators," IEEE Trans. Ind. Appl, vol. 12, no. 2, pp. 192-198, 1976.

[3] F. L. Tofoli et al., "Survey on nonisolated high-voltage step-up DC-DC topologies based on the boost converter," IET Power Electron, vol. 8, no. 10, pp. 2044-2057, 2015.

[4] M. Forouzesh et al., "Step-up DC-DC converters: A comprehensive review of voltage boosting techniques, topologies, and applications," IEEE Trans. Power Electron, vol. 32, no. 12, pp. 9143-9178, 2017.

[5] R. D. Middlebrook, "Transformerless dc-to-dc converters with large conversion ratios," IEEE Trans. Power Electronics, vol. 3, no. 4, pp. 484-488, 1988.

[6] D Maksimovic and S. Cuk, "Switching converters with wide dc conversion range," IEEE Trans. Power Electron, vol. 6, no. 1, pp. 151-157, 1991 .

[7] F. L. Luo and Y. Ye, "Positive output cascade boost converters," IEE Electr. Power Appl, vol. 151, no. 5, pp. 590606, 2004

[8] R. Lorea-Palomo and J. A. Morales-Saldana, "Family of quadratic step-up DC-DC converters based on non cascading structures," IET Power Electron, vol. 8, no. 5, pp. 793-801, 2015.

[9] M. I. Nejad et al., "New cascade boost converter with reduced losses," IET Power Electron, vol. 9, no. 6, pp. 12131219, 2016.

[10] J. Chen et al., "Cascaded high voltage conversion ratio bidirectional nonisolated DC-DC converter with variable switching frequency," IEEE Trans. Power Electron, vol. 33, no. 2, pp. 1399-1409, 2018

[11] R. Hosoki, S. Kinjo, and H. Koizumi, "Ripple free operation of two-stage boost type DC-DC converter," Proc. IEEE Industrial Electronics Conference, 2015, pp. 577-582.

[12] S. Hayano and N. Hoshi, "Efficiency characteristic of cascaded multistage boost converter," Proc. IEEE Industrial Electronics Conference, 2016, pp. 1324-1329.

[13] O. Lopez-Santos et al., "Steady-State analysis of inductor conduction modes in the quadratic boost converter," IEEE Trans. Power Electron, vol. 32, no. 5, pp. 2253-2264, 2017.

[14] J. A. Morales-Saldana et al., "Multiloop controller design for a quadratic converter," IET Electr. Power Appl, vol. 1, no. 3, pp. 362-367, 2007.

[15] C. Y. Chan, "Investigation of voltage-mode controller for cascade boost converter," IET Power Electron, vol. 7, no. 8, pp. 2060-2068, 2014.

[16] S. Choi et al., "Analysis, design and experimental results of a floating-output interleaved-input boost-derived DCDC high-gain transformerless converter," IET Power Electron, vol. 4, no. 1, pp. 168-180, 2011.

[17] M. Kabalo et al., "Experimental validation of high-voltage-ratio low-input-current-ripple converters for hybrid fuel cell supercapacitor systems," IEEE Trans. Vehicular Tech, vol. 61, no. 8, pp. 3430-3440, Oct. 2012.

[18] P. A. Dahono, "Derivation of high voltage-gain step-up DC-DC power converters," International Journal of Electrical Engineering and Informatics, vol. 11, no. 2, pp. 236-251, Jun. 2019.

[19] R. Giral, L. Martinez-Salamero, and S. Singer, "Interleaved Converter Operation Based on CMC," Trans Power Electron, vol. 14, no. 4, pp. 643-652, Jul. 1999.

[20] P. A. Dahono et al., "Output Ripple Analysis of Multiphase DC-DC Converters," Proc. IEEE Power Electronics, Drives, and Systems Conference, 1999, pp. 626-631.

[21] P. W. Lee et al., "Steady-State Analysis of an Interleaved Boost Converter with Coupled Inductors," IEEE Trans. Ind. Electron, vol. 47, no. 4, pp 787-795, Aug. 2000.

[22] R. D. Middlebrook and S. Cuk, "A general unified approach to modelling switching-converters power stages," Proc. IEEE Power Electronics Specialist Conference, 1976, pp. 18-34. 
[23] J. H. Rockot, "Losses in High-Power Bipolar Transistors," IEEE Trans. Power Electron, vol. 2, no. 1, pp. 72-80, Jan. 1987.

[24] P. A. Dahono, Y. Sato, and T. Kataoka, "Analysis of Switching and Conduction Losses in Hysteresis Current Controlled Inverters," IEE Japan Trans. Industry Appl, vol. 113-D, no. 10, pp. 1216-1225, 1993.

[25] F. Blaabjerg, U. Jaeger, and J. K. Padersen, "Power Losses in PWM-VSI Inverter Using NPT or PT IGBT Devices," IEEE Trans. Power Electron, vol. 10, no. 3, pp. 358-367, May 1995.

[26] F. Xue et al., "Loss Analysis of GaN Devices in an Isolated Bidirectional DC-DC Converter," Proc. IEEE Workshop on Wide Bandgap Power Devices and Applications, 2015, pp. 201-205.

[27] F. Pulsinelli et al., "Power Losses Distribution in SiC Inverter Based Electric Motor Drives," IEEE Trans. Ind. Appl, vol. 55, no. 6, pp. 7843-7853, 2019.

\section{BIOGRAPHY OF AUTHOR}

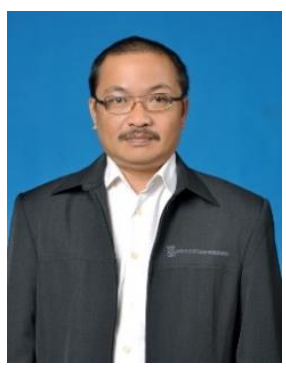

Pekik Argo Dahono received bachelor degree from the Institute of Technology Bandung, Indonesia, in 1985, Master of Engineering and Doctor of Engineering degrees from the Tokyo Institute of Technology, Japan, in 1992 and 1995, respectively, all in electrical engineering. At present, he is a professor in the School of Electrical Engineering and Informatics, Institute of Technology Bandung. He has interests in power electronics, power quality, and industrial power systems. He is a cofounder of Indonesia Power Quality Initiatives and Indonesia Smart Grid Initiatives. He has published more than 100 international and national papers. He is recipient of ASEAN Engineer Outstanding Achievement Award in 2006 and 2014. He is registered as a professional engineer in Indonesia and ASEAN. He is a senior member of IEEE. He was a Hitachi Post-Doctoral Fellow in Tokyo Institute of Technology, Japan, in 1997-1998. He was a visiting professor in Tokyo Institute of Technology, Science University of Tokyo, and Tokyo Denki University, in 1998, 2001, and 2004, respectively. He was also a visiting professor in University of Toulouse, France, in 2008. 